\title{
Geological Risks Management and Reduction Procedure for Santiago Cuba Province
}

\author{
Galban Liber Rodriguez'1, Rafael Saved Lacaba², Chuy Jacinto Tomas Rodriguez ${ }^{3}$, \\ Noelia Vidaud Ingrid Quintana ${ }^{4}$ \\ ${ }^{1}$ Department of Hydraulic Engineering, Faculty of Construction, Universidad de Oriente, Santiago de Cuba, \\ Cuba \\ ${ }^{2}$ Department of Geology, Faculty of Geology and Mines, Mining Metallurgical Institute, Holguin, Cuba \\ ${ }^{3}$ National Center for Seismological Research (CENAIS), Santiago de Cuba, Cuba \\ ${ }^{4}$ Faculty of Construction, Civil Engineering Department, Universidad de Oriente, Santiago de Cuba, Cuba \\ Email: liberg@fco.uo.edu.cu, rguardado@ismm.edu.cu, chuy@cenais.cu, ingrid@fco.uo.edu.cu
}

Received 5 July 2014; revised 18 August 2014; accepted 22 September 2014

Copyright (C) 2014 by authors and OALib.

This work is licensed under the Creative Commons Attribution International License (CC BY).

http://creativecommons.org/licenses/by/4.0/

(c) (i) Open Access

\begin{abstract}
Santiago de Cuba Province due to its seismicity, mountainous relief, lithological composition and stratigraphy, tectonic conditions, hydrological and geotechnical conditions, is regarded as the greatest potential for manifestation of geological hazards Cuba. The analysis of this province, notes that there are problems in the geological engineering study, land use and planning, organization, evaluation, management, analysis, implementation, monitoring and control of geological risks in the territory, meaning that management problems exist. To resolve these problems, this research proposes a new procedure for management and reduction of geological risk in Santiago de Cuba province supported by the theoretical foundations of processes management.
\end{abstract}

\section{Keywords}

Santiago de Cuba, Risks, Geology, Disaster Management

Subject Areas: Environmental Sciences, Geology

\section{Introduction}

The consideration of geological events (earthquakes, landslides, erosion, karst, floods, etc.) is an important task for process engineering, physical planning and disaster reduction, due to its influence on ground stability, deterioration of rocks and soils, the variation of the relief of the earth's surface, changes in hydrographic networks and respectively in existing works, planned, under construction, etc., (Cities, buildings, bridges, dams, roads, tunnels, airports, mines, quarries) as well as in the development of society in general. The occurrence of these events may 
constitute hazards whose impact can trigger geological risks.

Geological risks are understood as any process, situation or event in the geological, natural, induced or mixed environment, which can generate economic or social harm to any community, in whose prediction, prevention or correction, geological criteria should be employed [1].

In Cuba, the issue of whether they are natural or man-made hazards, exists within an organizational management structure headed by the Civil Defense, the Ministry of Science Technology and Environment (CITMA) and municipal and provincial governments of the People. They have legislated aspects of tasks that must be developed, and promoted a wide range of actions in order to cope with the possible tools and in the best conditions, the various situations that arise, to reduce the damage caused by various events. In recent years, the available information on natural hazards, monitoring of hazardous events - especially hydro, seismic - and warning systems to the population in the country has been improved. However, this system has proven in practice the need for mitigation and management of geological hazards. There have been many economic losses, environment and human life caused by these events: the earthquake that took place in the city of Santiago de Cuba (1932 and 1947), recent landslides in the provinces of Guantanamo, Holguin, Santiago de Cuba and Granma [2], as well as events occurring in the eastern provinces following Hurricane Sandy in October 2012 which bore this out.

Considering the extent of the Cuban archipelago, a study was made of the threat situation and geological hazards in the Santiago de Cuba province because of its geological engineering conditions, seismicity and tectonic conditions, lithological and structural characteristics, mountainous terrain and hydrographic conditions and geotechnical conditions is regarded as the greatest potential geological hazards and risks in the country.

Overall, the number of victims in the province by the materialization of risks has decreased, suggesting increased efficiency in preparation and attention, but the damage after Hurricane Sandy by the province of Santiago de Cuba, demonstrates that the magnitude and cost of the same have increased, indicating that the vulnerability of the goods has not declined, nor have taken sufficient steps for proper management of geological hazards. This analysis indicates that in Santiago de Cuba province there exist some deficiencies in the geological engineering study, land use, planning, organization of actions, risk assessment, measures implementation, monitoring and controlling, meaning that management problems exist.

\section{Engineering Geological Characterization of the Main Geological Hazards and Risks in the Santiago de Cuba Province}

The Santiago de Cuba Province is located south of the eastern region, between $19^{\circ} 53^{\prime}, 20^{\circ} 12^{\prime}$ north latitude and $75^{\circ} 22^{\prime}, 77^{\circ} 02^{\prime}$ west, bordering the west by Granma, the Holguin north, east and south Guantanamo by the Caribbean Sea. Its capital is the city of Santiago de Cuba, the second most populated (over 500,000). The province has a total area of $6234.16 \mathrm{~km}^{2}$, a total population of 1,053,837 inhabitants (2012), is divided into nine municipalities: Guama, Santiago de Cuba, Palma Soriano, Second Front, Third Front, Songo the Maya, Petty, San Luis and Julio to. Mella (3). With regard to climate, Santiago de Cuba is one of the country's hottest provinces, with an average maximum temperature of $32.3^{\circ} \mathrm{C}$ and an average low of $23^{\circ} \mathrm{C}$ in the capital city, total mean annual rainfall is $1393.9 \mathrm{~mm}$, in the mountains are cooler temperatures and more rainfall [3] (Figure 1).

The topography of the province is varied. To the northeast is semi-mountainous and accidental, comprising young elevations where slopes exceed $25 \%$ in some cases and to the northwest is relatively flat with the development of floodplains and watersheds of economic interest. Much of the territory of the province is covered by the Sierra Maestra with the highest peaks of the island (Pico Turquino, $1974 \mathrm{~m}$, Pico Cuba, $1874 \mathrm{~m}$ and Pico Sweden, $1734 \mathrm{~m}$ ), and the Sierra de la Gran Piedra (hill of the Great Stone $1226 \mathrm{~m}$ ). In mountainous areas, mainly in the municipalities Guama, the southern part of Third Front and east of the municipality of Santiago de Cuba, there are slopes that exceed 50\%, which favors the effects of erosion and landslides. Only $3 \%$ of the total area of the province is below the elevation of 100 meters above sea level.

The basin of Santiago de Cuba is framed as a major accident to the center south of the province, where several levels of terraces and plateaus that depart from the Bay of Santiago de Cuba (Length: $8.5 \mathrm{~km}$, width $2.4 \mathrm{~km}$, depth: between 8.8 and $13.7 \mathrm{~m}$ ) around which develops the city of the same name, looking at the top several floodplains [4].

The hydrography (both southeast and the southwest part of the province) is composed of short dashes rivers, rapids and intermittent in most parts of the year due to the morphology of the relief, which in the rainy season carry large amounts of sediments to the lower parts of the basins, so its erosive activity is significant. Among the most 


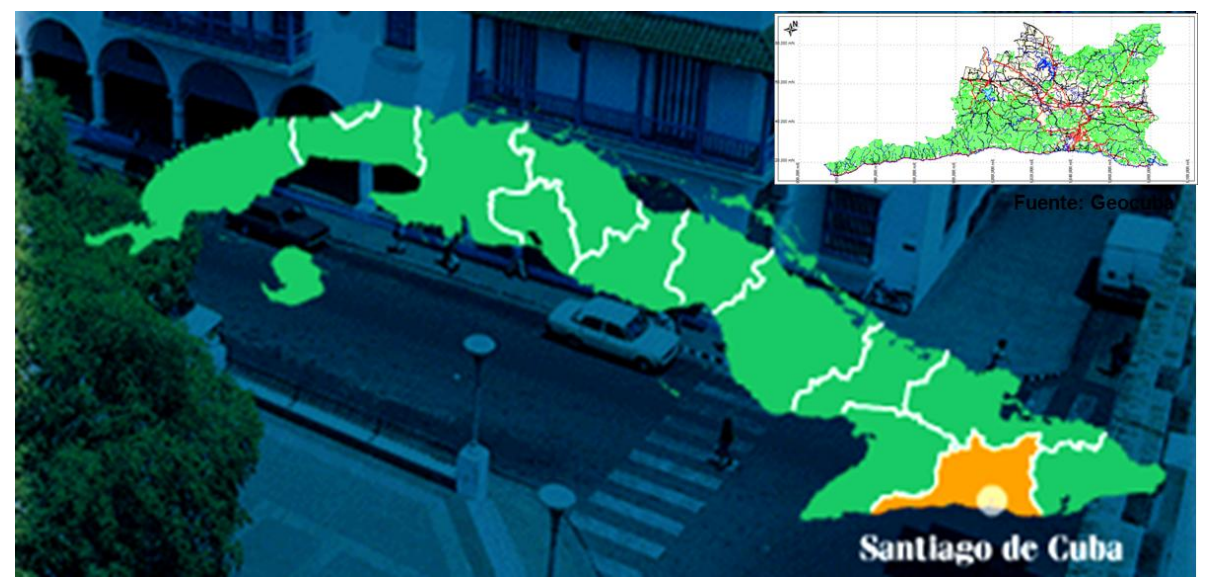

Figure 1. Location of Santiago de Cuba province in Cuba.

important rivers in the southern part Chivirico cite, Sevilla, Stops, San Juan, Daiquiri and Baconao. In the northwest are the major river basins, which are located the two largest reservoirs in the province (Protest Baraguá and Carlos Manuel de Céspedes) for Cautious and Boatswain rivers respectively.

Geologically, the mountain ranges in the south of the province is dominated by granitic type igneous rocks to the southeast basin mafic around Santiago, the type volcanogenic and sedimentary on various correlations, and highly variable alternating combinations, both vertically and laterally. The sedimentary rocks of the type dominant in Santiago Basin (south central) and in the southern part of the province, showing an alternation of limestones biodetritics, silty limestones and silty-clayey, loamy matrix calcarenites, marls, and subordinately aleurolits clays, conglomerates and sandstones with calcareous cement polymictic, consisting mainly of volcanic, although it is also possible to find the southeast mainly metamorphosed [5].

Stratigraphically the oldest formations are from the Cretaceous period, with formations dominated sedimentary, volcanogenic and sedimentary vulcanogenic. They also represent the Paleogene formations, abundantly re-presented within the group formations Copper widely distributed along the Sierra Maestra. Within the Neogene geological evolution are a group of mainly carbonate sedimentary formations. The most recent formations, predominantly sedimentary, belong to the Quaternary and evolve discontinuously in small areas of the basin of Santiago de Cuba [5].

According to Nagy et al. (1983) [6] in the southern region of eastern Cuba, the structural geomorphology, fault systems, stratigraphic and lithologic conditions and evolution of eastern Cuba, are elements that determine seismotectonic conditions of this region; therefore achieving various geological hazards and risks, including earthquakes, landslides, erosion, karst, floods, and other anthropogenic.

The areas of greatest seismic hazard in the province are south of the city of Santiago de Cuba, the town of Chivirico (municipality Guama, west) and Baconao area (to the east), coinciding with the areas where there are three generators earthquake centers south of eastern Cuba. The study level reached in the basin of Santiago de Cuba makes possible liquefaction assessments as a side effect. Almost the entire lower area around the bay of Santiago de Cuba is highly exposed to the effects caused by this phenomenon [7]. This means that buildings and infrastructure located in the environment have a high degree of vulnerability to the occurrence of soil liquefaction.

According to Arango and Pino (2007) [7], there are probabilities of occurrence of tsunamis or tidal waves in the study area, affecting the counties located in the vicinity of coastal areas, locating the foci generators along the fault system Battle-Cayman, complicating element seismic hazard Santiago province to possess several communities in low-lying areas near the coast.

Erosive activity in Santiago de Cuba is high due to the mountainous conditions of the province with marked slopes and the presence of moderately compacted sedimentary rocks vulcanogenic with considerable power, especially to the south. Predominates fluvial erosion generated during the rainy season and coastal erosion. There are different manifestations of affectations, especially infrastructure projects located in mountain areas (roads, highways, bridges, etc.). Of municipalities Palma Soriano, San Luis, Second Front, Third Front, Guama, The Maya and Santiago de Cuba.

According Castellanos et al. (2006) [8], Perez (2007) [9] and others, landslides have appeared in a timely 
manner and located in the province, although susceptibility to this phenomenon is elevated geological engineer present conditions in the territory. Among the causes that lead to the formation of landslides are: the increase in the slope of hillsides or slopes, weakening the strength of the rocks as a result of the change in their physical condition, the action of the hydrostatic forces and hydrodynamics on the rocks that cause deformation, seepage, bulging of the soil and fluent transition to state as well as the variation of the stress state of rocks in the slope product constructive actions, the mining and the external effects which cause fluctuations micro-seismic and seismic territory, particularly the municipalities Guama and Santiago de Cuba. Each of these causes separately can cause landslides, but most often is observed in combination influence.

Cabrera and Santos (2007) [10] among others, emphasize that the main effects for endangered karst in the south east of the country, and consequently in the province of Santiago de Cuba, are found in the nearshore areas where infiltration generates high mantle groundwater, cavitation damage and therefore different infrastructures, facilitating also achieving some differential settlements in certain areas. Other manifestations may be related to the collapse of some walls karst formations that are close to the coast, forming terraces in Santiago basin and Baconao area where several buildings have been located and infrastructure.

Flooding in Santiago de Cuba occur most frequently in the municipalities Second Front, Palma Soriano, Santiago de Cuba Guama and, in the case of the latter, areas of the city as Yarayó, Jesus Menendez Avenue, Los Cangrejitos and Power Plant (for cite a few examples), have been affected by frequent flooding, mainly due to the change in land use and poor sewage drainage [11].

The saturation of soils is a common phenomenon in some areas near the alluvial river valleys Cautious, Petty, San Juan and others located in the coastal zone, which usually present all year round runoff. This is a factor by the type of lithology exhibiting these areas (alluvial deposits, sedimentary rocks, marsh and low cohesion), enhances the effects of earthquakes on the infrastructures at these locations, and accelerates the deterioration of these to increase moisture in the foundation, interior and exterior walls.

The effects caused by the presence of expansive soils are geotechnical hazard type and are also present in Santiago de Cuba province affecting different areas, especially in the city of Santiago de Cuba. Several examples confirm the inadequate consideration of this threat and therefore its management. The vulnerability to this hazard is present in the use of inadequate building systems for high seismic risk areas. Specialists state that branch constructive Giron systems are not the most suitable for these areas, at least without changes to be made in the design of the foundations and the general structure, however, are extended in the province without significant structural changes.

These elements show limitations in the management of geological hazards in the province of Santiago de Cuba, because this shows that not enough good risk assessment process, but also it is necessary to transform the work strategies and personal preparation made interventions to reduce vulnerability. It is also necessary to increase the organization and controls the implementation of mitigation measures and risk reduction, hence to improve continually the actions taken to reduce vulnerability increases the safety of people, goods and services.

\section{Procedure for Management and Geological Risk Reduction}

In the world there have been many tools working in various areas of human development under the principle of management by processes, which do not include geological risk management into their applications, although there can be matches with other forms of risk management. If you need to understand the process approach applying fundamentals to geological risk management is necessary to extrapolate its components, for example, the "organization" could be the set of institutions that make up the risk management system, the "client" would be represented by the investor or the community, "processes" are the stages of a project or phase of a system, among these, the assessment of risks, "threads" may be the actions that must be performed to ensure that risk assessment. There is no difficulty in the interpretation and application of the general principles of the process approach to the management of geological hazards. We can say then that it is right to adopt. Making the necessary adjustments to the procedure proposed follows a general work structure as proposed in the Figure 2.

\subsection{System Diagnostics Process for Geological Risk Management in the Province}

Diagnose a system means to study the state in which they are components. Given this approach, in this process it is necessary to perform the following threads:

- Knowing the Risk Management System in the province Geological establishing guidelines for their operation. 


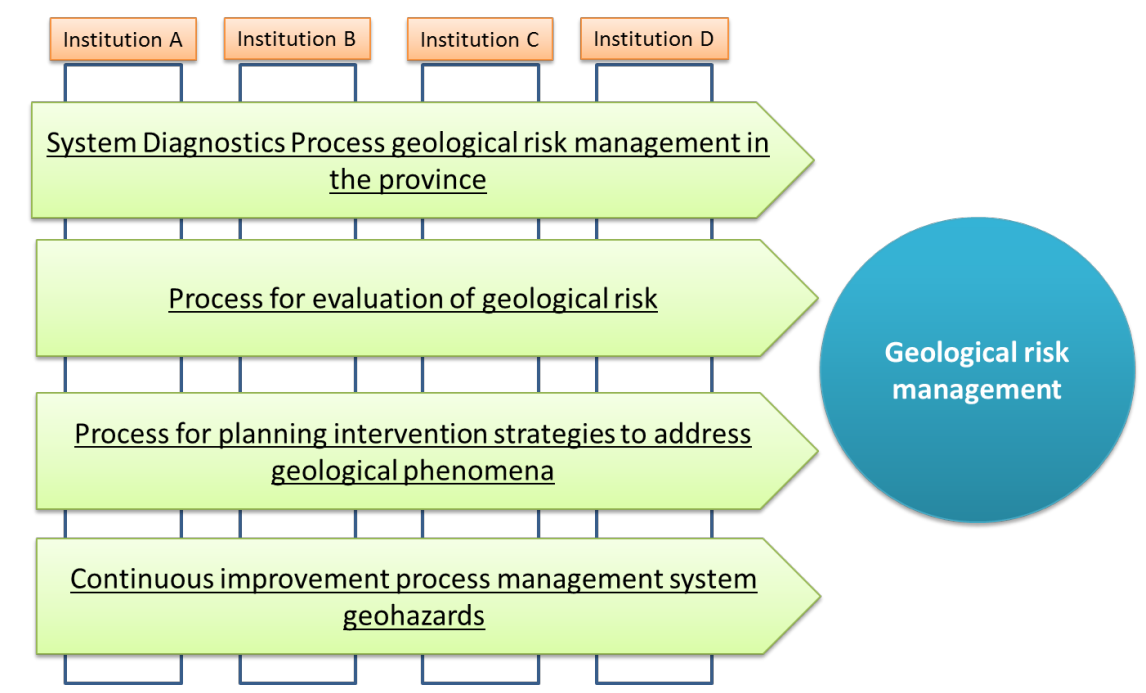

Figure 2. Scheme of the procedure showing the relationship between processes and geological risk management purpose.

- Creation and legalization advisory group to risk management centers.

- Issuance of technical tasks geological risk assessment.

- Forming processes sheets for each entity that makes up the system.

The management system of geological hazards should build on the knowledge of what are the main entities and elements involved in the reduction and mitigation of various geological hazards in the province, as well as reviewing their working relationships and results with order to establish multidisciplinary integration mechanisms. The creation and legalization of the group of advisors to risk management centers allows multidisciplinary participation and mission specialists and technical tasks geological risk assessment are intended to indicate the necessary evaluations to perform future actions. Processes tokens for each entity that integrates the system is essential, because in these fundamental data are identified, structure, departments, specialists involved in the system and perform specific tasks, ensuring all essential aspects for multi-disciplinary integration.

\subsection{Process for Evaluation of Geological Risk}

The goal of this process is to provide and disseminate data, information and knowledge that will facilitate the effective management of geological risk, so as to be affordable to those who have to make decisions later. Threads for assessing geological hazards are:

- Characterization of the main geological hazards in the province.

- Set geological-geotechnical mapping and its adaptation to a scale that provides basic information for subsequent work.

The geological risk assessment should be carried out considering several phases. Furthermore it is necessary to take into account issues related to:

- Establishing indicators geological risk assessment.

- Standardization of these indicators of hazard assessment, vulnerability and geological risks (HVR).

- Progressive Establishment engineer scales geological studies aimed at achieving ever greater detail.

To establish geohazards indicators assessment, we propose a manual that express the same, based on the experiences of both international and domestic. Standardization suggested classifying HVR on a scale of zero to one (0 - 1) levels following as follows (Table 1).

For the preparation of the maps were taken into account five types according to their scale mapping working: 1 ) Nationwide; 2) Regional scale; 3) Scale Media; 4) Detailed Scale; 5) Research site.

\subsection{Process for Planning Intervention Strategies to Address Geological Phenomena}

This process is aimed at progressive action planning they allow the current state to the desired state, establishing 
Table 1. Classification and standardization of HVR values.

\begin{tabular}{ccccc}
\hline & 1st Level & 2nd Level & 3rd Level \\
\hline Hazard & None-Low $(0-0.25)$ & Moderate $(0.26-0.5)$ & Stop $(0.51$ to 0.75$)$ & Very High $(0.76$ to 1$)$ \\
Vulnerability & None-Low $(0-0.25)$ & Moderate $(0.26-0.5)$ & High $(0.51$ to 0.75$)$ & Very high $(0.76$ to 1$)$ \\
Risk & None-Low $(0-0.25)$ & Moderate $(0.26-0.5)$ & Stop $(0.51$ to 0.75$)$ & Very High $(0.76$ to 1$)$ \\
\hline
\end{tabular}

development plans and address the various processes of land use and physical planning carried out in the province. Among the elements that should be addressed are primarily:

- Rating System for physical planning according to the degree of complexity and importance of social and economic considerations of the costs of mitigation of geological risks.

- Issuance of legal rules at the territorial level of system performance.

- Establishing a training plan preparation and intervention groups, education and outreach to the general public, of geological hazards to which it is subjected.

- General design and implementation of risk mitigation measures in the territory geological to improve the current situation.

The classification of the works according to their degree of complexity and socio-economic importance, plays an important role in determining the detailed conditions required geological engineering geological hazard studies, due to potential damage it can cause in certain exposed sites geological hazards; reason we propose a new classification for planning and construction projects, considering the costs of geological risk reduction.

To design mitigation measures are introduced geohazards the following:

- Introduction of conclusive reports geohazards assessment for projects, which should be named: State Geological Situation Update (ESGA).

- Design mitigation measures geohazards. For what it may use different structural and nonstructural measures, as well as indicators for evaluation, professional software can also use physical-mathematical modeling to verify its effectiveness.

The ESGA is a report containing a comprehensive evidence base geological and geotechnical and geological hazards in the area of interest for the implementation of a project. The data that form the ESGA are the result of all the research on geological and structural engineering performed by both design engineers and companies providing geotechnical services, as the results provided by all institutions in the system management (scientific, government, teachers, etc.). Allowing fully understands the geological architecture of the site of interest and its current dynamics, so as to facilitate the foundation and sustainability of the process of decision-making and design of geological risk mitigation.

\subsection{Continuous Improvement Process for Geological Risk Management}

This risk management process is directly related geological monitoring and evaluation of activities in the processes outlined above and their feedback. Are defined for it the following threads:

- Constant updating of basic mapping of hazard, vulnerability and geological risks under changing conditions of the different scenarios of risk over time.

- Development of recommendations for the efficient exploitation of space and facilities, taking into account the evaluation of geoenvironmental phenomena, management plans and physical planning, amongst other tasks designed to reduce and mitigate geohazards.

- Continuous improvement of the risk management system of geological.

Continuous improvement, is a process of evaluating possible errors and implement improvements to the procedures, techniques or technologies used for assessing geological hazards and the proper functioning of the system. Experiences can be used in future projects, and establishing that once the implementation of the projects and their plans, these should be assessed through a number of measures, which will show the results in the incorporation of measures to mitigate geohazards.

The procedure processes are not closed systems, but is enriched with the ideas, according to the needs of each organization where employed. Your application has systemic and cyclical. This means you will always managing geohazards. In Cuba and have been taking important steps to enable the implementation of this procedure, these 
include: the introduction of ISO certifications in enterprises and institutions, the introduction of some research results, such as those proposed by Corpas (2009) [12], Ivonnet et al. (2007) [13], Guach (2009) [14], Fernandez et al. (2009) [15], among others, recently produced, as well as the inclusion of integrated management systems, including business improvement systems.

\section{Implementation of the Method Proposed in Santiago de Cuba Province}

\subsection{System Diagnostics Process for Geological Risk Management in the Province}

In Santiago de Cuba province has taken various measures relating to the management of natural disaster risks, including the creation of the Risk of Territorial Delegation CITMA, various measures have been applied, developed methodologies and other actions of a organization. Emphasizes the participation of organizations led by the government and the Civil Defense, among these, the CENAIS between their results showing the proposal of the Cuban seismic code (NC-46: 1999) [16], the headquarters of the Institute province Meteorology, the company Geocuba, the provincial and municipal centers risk management, and with them the PVR provincial group, the University of the East with a large scientific potential, the Construction Enterprise Group has in the company of Project Company 15 (EMPROY 15) an example of cutting edge in applying the principles of process management, etc.

Although there are various institutions and specialists who collaborate in order to manage geological risks, they are not conceived as a whole as a risk management system, because he proposes a system that has a group of institutions whose results have some level of implementation in the various programs and projects to be developed in the province

\subsection{Continuous Improvement Process for Geological Risk Management}

From the collaboration of institutions of the territory was obtained basic information for making digitized GIS projects. As a result, achieved a series of 34 maps including working medium scale $(1: 100,000-1: 50,000)$ that reflect aspects such as relief, digital terrain model (Figure 3), climate, hydrography, vegetation (Figure 3), geology, lithological susceptibility (Figure 3), geological hazards, geotechnical model susceptibility lithology, anthropogenic processes, risk models and geological hazard approach maps.

The interpretation of these maps and models to define that the greatest risk to landslides from earthquakes are located in the municipality of Santiago de Cuba and to a lesser extent Guama (mostly Copper Group formations), while in the case of landslides by rainfall is municipalities in Guama, Third Front, Northern Second Front and the southern part of Palma Soriano, coinciding with high fluvial erosion that occurs in these areas (El Cobre Group formations, Camaroncito Formation, upper formations El Caney, San Luis, Mícara, serpentinites II Front).

On the other hand, modeling of groundwater levels and its combination with lithological susceptibility resulted in the areas most susceptible to the occurrence of liquefaction are low-lying areas near the coast where rivers deposited alluvial sediments low compaction ( formations Maya, La Cruz, Rio Macío, El Caney, Jutía, alluvial formations of the group associated with El Cobre). These elements give the conclusion that communities and infrastructure located in these areas are the most threatened in the province, something that finally confirmed the variants obtained from engineer-geological zonation hazard approach.

\subsection{Process for Planning Intervention Strategies to Address Geological Phenomena}

In the analysis in the diagnostic process to organizations involved in the risk management system in the province, there is the necessary transformation of strategies with better approaches to the management aspects of geological hazards. Among the key strategic actions to achieve this goal are proposed:

- Progressively increase staff training in issues related to geological risk management communities, workplaces, etc., establishing systems of individual and collective evaluation.

- Work to link specialists to basic education centers for education increased responses to risk and disaster situations.

- Develop territorial legislation allowing all members of multidisciplinary teams conduct inspections of the implementation of its results in practice (construction works or other projects), depending tighten controls and improve response capabilities and quality systems to the impact of natural or man-made geological events.

- Direct actions to promote a policy of insurance to geohazards. 

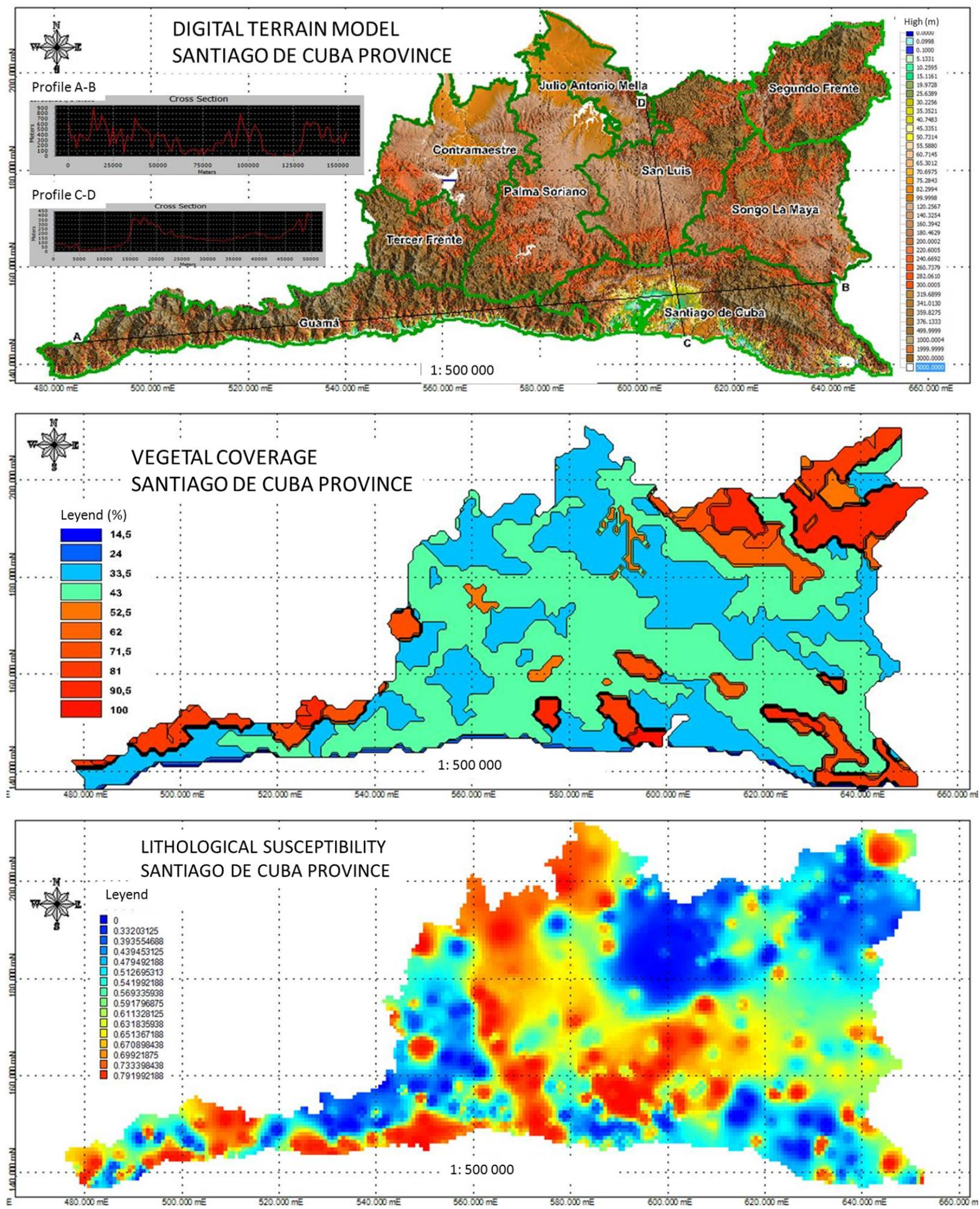

Figure 3. Images of obtained maps and models: digital terrain model, vegetal coverage and lithological susceptibility.

- Work to include additional special budget to ensure the structural safety of the works located in areas of high geologic hazard.

- Transforming the working system of the institutions of the territory towards the implementation of process management criteria of the ISO 9001, 18000 and 14000. 


\subsection{Process for Evaluation of Geological Risk}

To implement continuous improvement municipality was selected Santiago de Cuba as a model system representative of geological risk management in the province. From proposed in this research, the following actions are performed:

- Development of a GIS project to generate basic mapping of hazard, vulnerability and geological hazards for updating the database of the municipality.

- Introduction of a system of matrices for hazard, vulnerability and geological risks that identify areas most affected, leading indicators PVR assessment and tasks designed to improve the ability to respond quickly and effectively against every danger.

\section{Conclusions}

1) Nationally and internationally growing concern of specialists and governments on issues is related to risk management processes and geological disaster prevention. Their analysis shows that only from multidisciplinary integration and consistent application of new approaches, it is possible that a set of actions can be designed to reduce these risks and achieve sustainable development.

2) By characterizing the province of Santiago de Cuba, it was found that earthquakes, landslides, coastal and continental flooding and other anthropogenic processes, manifest as major geological risks generating events. It's inadequate consideration evidence deficiency in management.

3) We propose a method for reduction and management of geologic hazards. It is an effective tool, because it follows general patterns of process management and multidisciplinary participation. In this assessment of different indicators in the process, standardization in HVR assessments, considerations of work scales, the application of continuous improvement, among others, are new elements that allow dynamic introduction of various actions aimed at reducing the vulnerability present in Santiago de Cuba province.

4) The implementation of the procedure in the province of Santiago de Cuba allows the development of a geological risk management system, based on a set of new maps of hazard, vulnerability and risk. The proposition of different strategies and actions for improvement reduces the limitations identified.

\section{References}

[1] Ayala Carcedo, F.J. and Olcina Cantos, J. (2002) Natural Hazards. Editorial Ariel, Barcelona.

[2] Rosabal Dominguez, S., Balanqué Zapata, J.A. and Gomez, J. (2009) Incidence of Geomorphology in Negative Environmental Impacts Beltran Road, Guantanamo. Cuba Mapping Review, No.133, Spain.

[3] ONEI (2012) Statistical Yearbook of Cuba 2012. National Bureau of Statistics and Information. http://www.one.cu/aec2012/20080618index.htm

[4] García Peláez, J.A., et al. (2002) Final Report Project: Seismic Risk Map of Santiago de Cuba City. CENAIS-CITMA.

[5] Carrillo, D., Echavarria, B., Castellanos, E., Triff, J. and Nunez, K. (2009) Stratigraphic Lexicon of Cuba. Institute of Geology and Paleontology, Havana.

[6] Nagy, E., et al. (1983) Contribution to the Geology of Eastern Cuba. Institute of Geology and Paleontology, Acc Scientific and Technical Publishing, Havana, 273.

[7] García Peláez, J.A., et al. (2002) Final Project Report: Seismic Rik Mao of Santiago de Cuba City. National Seismological Research Center of Cuba (CENAIS).

[8] Arango Arias, E. and Del Pino Boytel, J. (2007) Geologic Hazards Associated with Northern Caribbean Geodynamics: Tsunami Hazard for Cuba. Proceedings on CD-ROM, 2nd Cuban Convention on Earth Sciences, GEOCIENCIAS 2007.

[9] Castellanos, E., et al. (2007) Application of Geophysical Techniques for the Characterization of Landslides in Cuba. Scale 1:250,000. Institute of Geology and Paleontology. Proceedings on CD-ROM, 2nd Cuban Convention on Earth Sciences, GEOCIENCIAS 2007.

[10] Pérez Rodríguez, M. and Norman Vega, A. (2007) Main Environmental Impacts Provocated by Geological Proceses in the Great Caribe. Proceedings on CD-ROM, 2nd Cuban Convention on Earth Sciences, GEOCIENCIAS 2007.

[11] Cabrera Castellanos, M. and Santos Hernandez, R.M. (2007) Geomorphologic Map of Marine and Coastal Territory of Cuba 1:1000 Scale 000. Proceedings on CD-ROM, 2nd Cuban Convention on Earth Sciences, GEOCIENCIAS 2007.

[12] Chuy Rodriguez, T.J. and Puente Gonzalez, G.(2005) Impact of Natural Phenomena. An Assessment Essential for 
Sustainable Development of Coastal Areas of Santiago de Cuba. CD Proceedings, International Conference on Integrated Coastal Zone Management, CARICOSTAS 2005.

[13] Corpas Toledo, A. (2009) Technological Package to Enginiering Geology Research. Proceedings on CD-ROM, 3rd Cuban Convention on Earth Sciences, GEOCIENCIAS 2009.

[14] Ivonnet Borrero, H. and Pino Santiesteban, E. (2009) Model of the Integrated Monitoring System for Environmental Impact in Hydraulic Works. Proceedings on CD-ROM, 3rd Cuban Convention on Earth Sciences, GEOCIENCIAS 2009.

[15] Guach Hechavarría, F. (2009) Models to Geological Risk Managements. Proceedings on CD-ROM, 3rd Cuban Convention on Earth Sciences, GEOCIENCIAS 2009.

[16] Fernández de la Cruz, C., et al. (2009) Methodology to Evaluate Aspect and Environmental Impacts in Areas Link with Key Processes of CEINPET. Proceedings on CD-ROM, 3rd Cuban Convention on Earth Sciences, GEOCIENCIAS 2009. 